\title{
RELAÇÃO ENTRE OS ESPAÇOS VAZIOS ENCONTRADOS NO LEITO DE PELOTAS EM UM FORNO DE GRELHA MÓVEL E OS CUSTOS COM ENERGÉTICOS E A PRODUTIVIDADE*
}

\author{
Marcos Vinícios da Silva Cavalcante ${ }^{1}$ \\ Renato Minelli Figueira ${ }^{2}$ \\ Sérgio Fernando Nunes ${ }^{3}$
}

\section{Resumo}

O processo de um forno de endurecimento de pelotas cruas tipo grelha móvel baseia-se na queima de esferas, aglomerados de minério de ferro, acomodados no interior de carros de grelha que se movimentam com certa velocidade através das zonas do forno. Neste tipo de forno as pelotas cruas são queimadas predominantemente por convecção por gases aquecidos via queimadores instalados na zona de queima. Estes gases quentes passam por entre as pelotas com uma velocidade, densidade, viscosidade e temperatura tal que garante a secagem, a sinterização e o resfriamento das pelotas enquanto são movimentadas dentro dos fornos. A permeabilidade de um leito de pelotas é uma função direta dos espaços vazios formados pelo empacotamento destes aglomerados esféricos que o compõe. Este estudo validado na linha de produção teve como objetivo relacionar os espaços vazios com alguns parâmetros de controle operacional usuais na indústria de pelotização e associá-los a qualidade física, produtividade e ao custo de produção.

Palavras-chave: Espaços vazios; Produtividade; Custos; Pelotização.

\section{RELATIONSHIP BETWEEN THE VOIDS FOUND IN PELLETS BED IN A FURNACE TYPE TRAVELING GRATE WITH ENERGY COSTS AND PRODUCTIVY}

\begin{abstract}
The process of a furnace hardening of raw pellets type traveling grate is based on burning of the spheres, iron ore pellets, accommodated in the interior of grid cars moving with a certain speed through the furnace zones. In this type of thermal treatment of the raw pellets are burnt predominantly by convection by heated gases from burners installed in the firing zone. These hot gases pass through the pellets at a velocity, density, viscosity and temperature such that guarantees drying, sintering and cooling of the pellets. The permeability of a pellet bed is a direct function of the voids formed by the packing of pellets that compose it. This study validated in production line aimed to understand the relationship of the voids with some common operating control parameters in the pellet industry and associate them with physical quality, productivity and production costs.
\end{abstract}

Keywords: Voids; Productivity; Costs; Pellet industry.

1 Eng.de controle e automação, Mestrando em engenharia metalúrgica e dos materiais na UFMG, Eng. de processos, Dep. pelotização, Samarco Mineração S.A, Anchieta, ES, Brasil.

2 Eng.Metalurgista, M.Sc., Ph.D., MBA Finanças, Professor Titular, Departamento de Engenharia Metalúrgica e de Materiais, UFMG, Belo Horizonte, MG, Brasil

3 Eng. Metalurgista, M.Sc, Engenheiro Especialista, Gerencia Geral de Operações, Samarco Mineração S/A, Anchieta, ES, Brasil. 


\section{INTRODUÇÃO}

O cenário mundial imprimido pela desvalorização do minério de ferro, figura 1 , tem impactado fortemente a margem de lucro das pelotizadoras em todo o mundo, pois 0 principal insumo na produção de pelotas são os finos de minério de ferro.

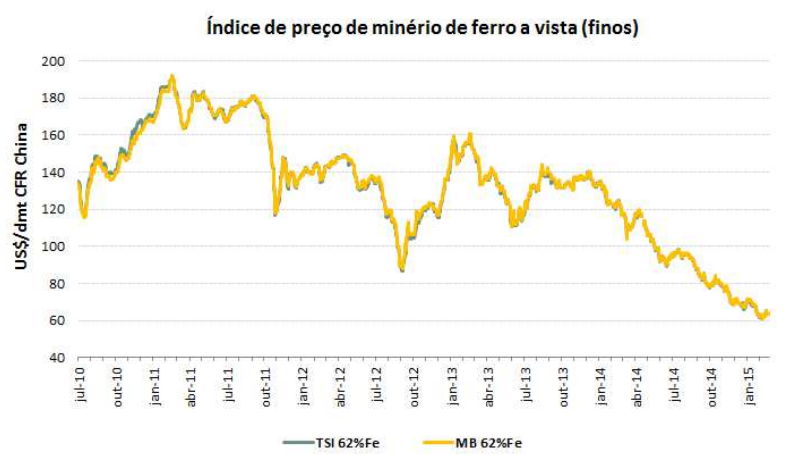

Figura 1. Preço do minério de ferro, janeiro 2015 [1].

A Samarco Mineração S.A, buscando minimizar as perdas em sua margem de lucro iniciou vários estudos internos buscando reduzir seus custos operacionais. Conforme resultados de experimentos em Pot-Grate, durante a queima foram percebidos menores deltas de temperatura para o mesmo delta de pressão entre as medidas realizadas sobre e sub o leito com diferentes características, o quê indicaria possíveis reduções de vazão de ar quente para garantir a mesma temperatura nas caixas de vento do forno, muito provavelmente em função da redução da tortuosidade (t) com o aumento dos espaços vazios $(\varepsilon)$, e com isso reduzir 0 consumo específico de combustíveis na queima e de energia elétrica com os ventiladores de processo. Ainda percebeu-se que existia um ponto ótimo do \%ع em que se maximizava a qualidade física a compressão, e como este índice é um fator restritivo de carga da grelha, e tê-lo otimizado significa dizer aumentar a produtividade da planta em sua plenitude, o objetivo deste estudo foi entregar um modelo de controle de custos e de produtividade a partir de parâmetros de controle operacionais (P.C.O) da unidade de processo pelotamento e ter os custos e a produtividade controlados em patamares ótimos.

\subsection{Processo Produtivo Relevante}

\subsubsection{Processo de Produção do Pellet Feed (Finos de minério de ferro)}

O principal objetivo deste processo é produzir concentrado de minérios de ferro, conforme a qualidade e quantidade requeridas, respeitando o orçamento, a segurança e a eficiência da cadeia produtiva. O Itabirito processado precisa ser concentrado, pois se trata de um minério pobre com aproximadamente $45 \%$ de teor de ferro. Através dos processos de moagem, britagem, flotação e espessamento, com dosagem de produtos químicos, obtêm-se teores de ferro de $68 \%$. Quando a polpa de minério de ferro, nome dado à mistura água mais minério de ferro, chega à marca de $70 \%$ de sólidos, este polpa é bombeada via mineroduto da Unidade Germano MG para a Unidade Ubu ES, onde ela é espessada, homegeinizada, filtrada e recebe o nome de pellet feed, ou concentrado. O concentrado é passado pela prensa de rolos para conferir características físicas adequadas tais como a superfície específica e o-325\#. Na mistura, processo seguinte, receberá aditivos tais como calcário, coque ou antracito/carvão, bentonita ou aglomerantes orgânicos, 
conferindo ao pellet feed características físicas, químicas adequadas aos processos seguintes, especialmente o de pelotamento e queima.

\subsubsection{Processo de Aglomeração das partículas de minério de ferro}

$\mathrm{Na}$ etapa de aglomeração do minério de ferro denominada de pelotamento, o minério de ferro devidamente preparado, com os aditivos necessários, é alimentado nos discos pelotizadores onde se inicia a formação das pelotas cruas. A carga é alimentada numa determinada posição do disco, Figura 2, que pode ser alterada, e as pelotas sofrem rolamentos sucessivos sobre as partículas finas alimentadas, acarretando o aumento gradativo do diâmetro das pelotas, Nunes [2].

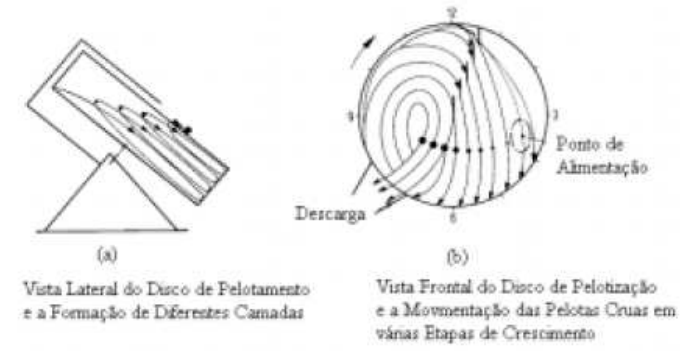

Figura 2. Disco de pelotização [3].

Após a saída das pelotas cruas dos discos pelotizadores, um sistema de classificação e transporte (mesa de rolos) permite a separação granulométrica de diâmetros de 2.0 a $16.0 \mathrm{~mm}$. Após a passagem na etapa de rolos o material maior que $16.0 \mathrm{~mm}$ é chamado de over-size, e o material menor que $16.0 \mathrm{~mm}$ é reclassificado e retirado os finos e é chamado de on-size que segue para a alimentação da grelha, Figura 3, de forma a garantir uniformidade e especificações requeridas pelos clientes.

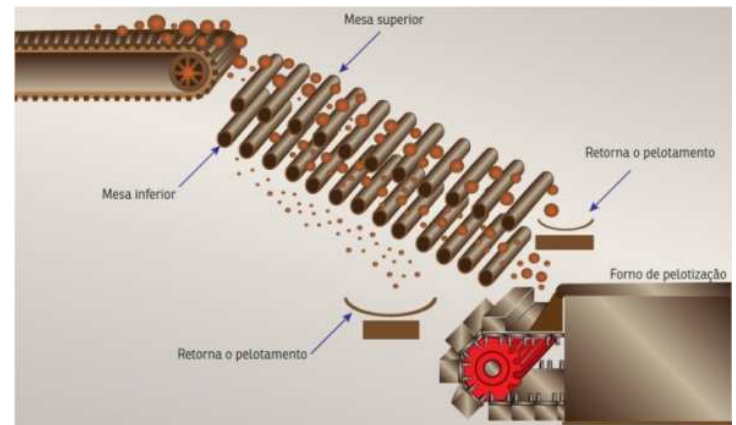

Figura 3. Sistema de classificação na alimentação da usina 03 [4].

\subsubsection{Processo de endurecimento em Forno de grelha móvel}

No processo de pelotização, uma das etapas mais importantes do processo é o endurecimento das pelotas de minério de ferro, Cota [5]. As pelotas cruas produzidas nos discos de pelotamento, após uma etapa de classificação em peneiras de rolos, são submetidas a um ciclo térmico adequado em um forno de endurecimento também chamado forno de pelotização. A Samarco Mineração opera fornos de pelotização do tipo Grelha Móvel. Objetiva-se com esta etapa do processo aumentar a resistência física das pelotas para que as mesmas possam resistir às operações de manuseio e transporte até o cliente, e também para que suportem os esforços mecânicos e os choques térmicos no interior dos fornos de redução, segundo Cota. 


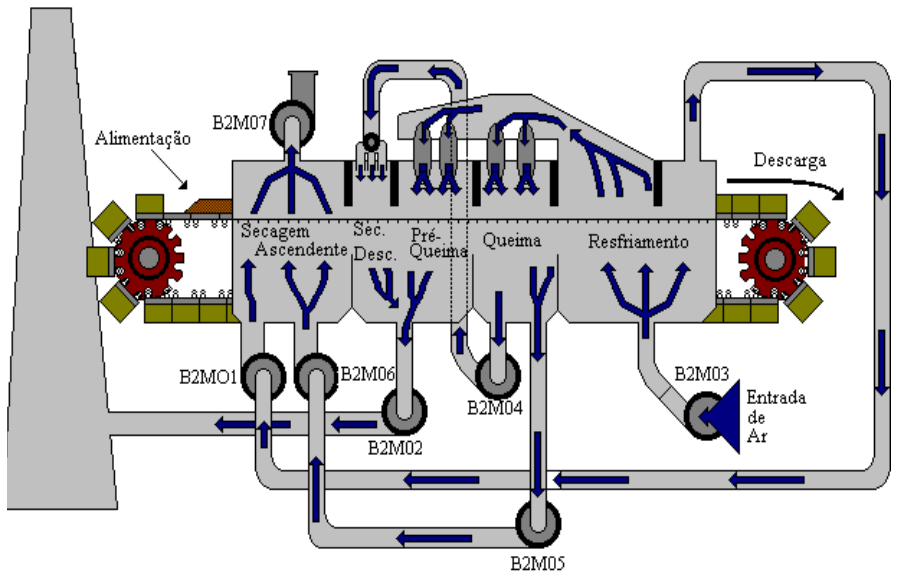

Figura 4. Fluxograma do Forno de endurecimento do tipo grelha móvel [6].

Nos leitos de pelotas o mecanismo de transporte de energia predominante é a convecção (Figura 5) diferente de outros sistemas de leitos de partículas, Athayde [7].

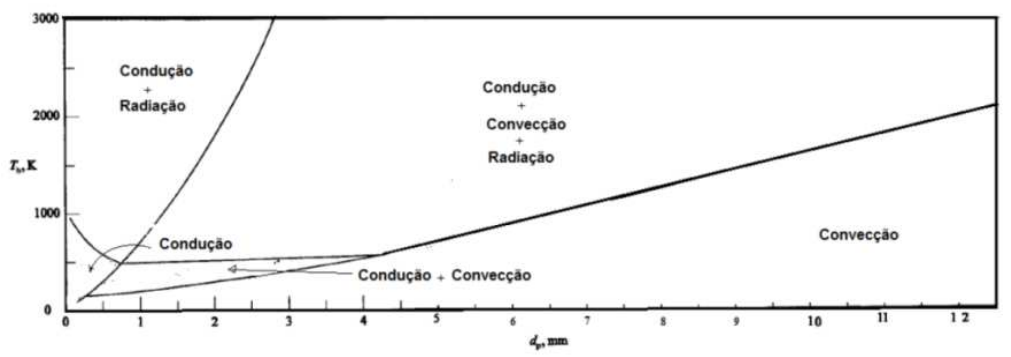

Figura 5. Mecanismos de transferência de calor em leito-gás em função de temperatura e diâmetro de partícula, adaptado de Flamant [8].

Segundo Cota [5], é notável a diferença de temperatura entre as camadas de pelotas da parte superior, intermediária e inferior do leito.

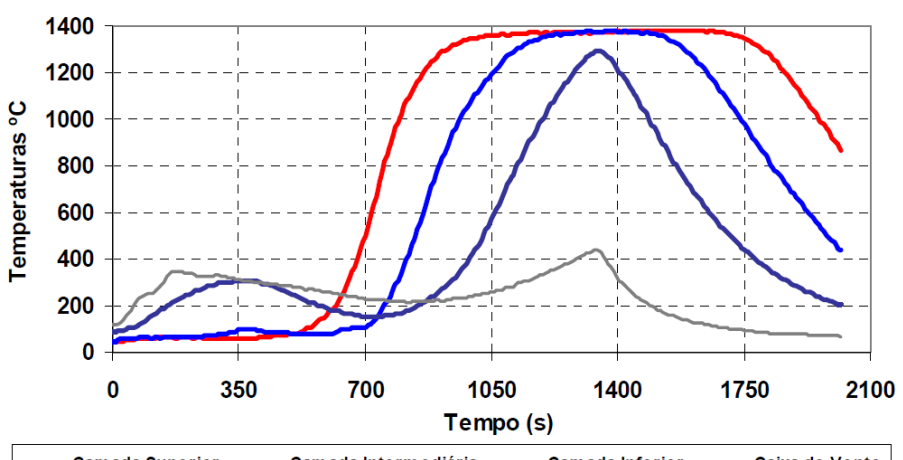

Figura 6. Perfil de temperatura nas camadas durante o ciclo de queima em Pot Grate [5].

\section{MATERIAIS E MÉTODOS}

\subsection{Medição de Diâmetro Médio e Granulometria no Leito de Pelotas Cruas}

As medições dos parâmetros de controle operacional, (P.C.O) tais como as faixas granulométricas de $-6.3 \mathrm{~mm}$; 8.0a6.3 mm; 16.0a8.0 mm; e +16.0 mm, diâmetro médio e relação granulométrica que é compreendida como a razão da faixa 16.0a12.5 mm com a faixa $12.5 a 9.0 \mathrm{~mm}$. Estas medições online são realizadas a 
partir de tratamento de imagens. As câmeras que capturam as imagens foram instaladas na entrada do forno gerando imagens superficiais do leito recém-formado, para evitar segregação de pelotas. Os dados são enviados via fibra-óptica para computadores de alto desempenho que tem como objetivo processar estas imagens a partir de um algoritmo dedicado que tem a função de entregar as medições, o acoplamento deste sistema com o modelo é mostrado na figura 7 .

\subsection{Modelo de Indicação do Percentual de $\varepsilon$ em Leitos de Pelotas}

O modelo matemático utilizado neste estudo foi desenvolvido internamente em PotGrate na Samarco Mineração S.A durante o estudo "Avaliação dos espaços vazios em leito de pelotas cruas e sua relação com os parâmetros de controle operacional do pelotamento medido em pot grate".

Sendo que:

$$
\text { Modelo } \boldsymbol{\varepsilon}=[a(D M)+b(16 a 8)+c(8 a 6.3)+d(-6.3)+e(+16.0)+f(R E L)] \beta
$$

- $\mathrm{DM}=$ Diâmetro médio $[\mathrm{mm}]$;

- $16 a 8$ = Faixa granulométrica menor que $16.0 \mathrm{~mm}$ e maior que $8.0 \mathrm{~mm}$ [\%];

- $8 a 6.3=$ Faixa granulométrica menor que $8.0 \mathrm{~mm}$ e maior que $6.3 \mathrm{~mm}[\%]$;

- -6.3 = Faixa granulométrica menor que $6.3 \mathrm{~mm} \mathrm{[ \% ];}$

- +16.0 = Faixa granulométrica maior que $16.0 \mathrm{~mm}[\%]$;

- REL = Relação granulométrica [-];

- $a, b, c, d, e, f$ são coeficientes encontrados durante o estudo acima mencionado;

- $\beta=$ Fator de ajuste do modelo $\varepsilon$ na planta industrial, usado neste estudo.

\subsection{Teste Industrial}

A partir das medições dos P.C.O. convertidas em \% $\%$ através do modelo $\varepsilon$ e das medições de consumo específico de carvão $(W)$, gás natural $(X)$, energia elétrica dos ventiladores de processo $(\mathrm{Y})$ e ainda temperatura na descarga das pelotas recém queimadas (Z), foi montado um banco de dados com 1500 médias de 20 minutos de cada uma das variáveis envolvidas durante o equivalente a 20 dias de produção de um tipo de pelota direcionado para o reator de redução direta. O período de amostragem não foi continuo, pois o teste seguiu a orientação do planejamento de produção, portanto os dados registrados foram coletados durante aproximadamente 3 meses.

Considerações importantes para tratamento dos dados industriais:

- W: Amostras de dados de consumo específico de carvão $[\mathrm{Kg} /($ produção de pelotas queimadas do período :[ton]));

- X: Amostras de dados de consumo específico de gás natural [KNm³/ton];

- Y: Amostras de dados de consumo específico de energia elétrica dos ventiladores de processo [Kwh/ton];

- Z: Amostras de dados de temperatura das pelotas na descarga $\left[{ }^{\circ} \mathrm{C}\right]$.

Custo específico utilizado, custo variável de $(\mathrm{W} ; \mathrm{X} ; \mathrm{Y} ; \mathrm{Z})$ :

- W: Consumo específico de carvão x Preço carvão $[R \$ /$ ton];

- $X$ : Consumo específico de gás natural x Preço GN [R $\$$ /ton];

- Y: Consumo específico de energia elétrica x Preço Energia Elétrica [R $\$ /$ ton];

- Z: Consumo específico térmico com perdas $\times$ Custo do Kcal/ton [R $\$ /$ ton]; 
- A matriz térmica utilizada no período confere uma razão média de 1,04 para a razão Kcal Carvão/Kcal Gás natural, [-];

- Taxa diária de produção de pelotas [ton/dia]; Work rate:351 [dias/ano].

\subsection{Modelo Sugerido pelo Estudo de Controle de Custos Operacionais em Pelotização (M.C.C.O.P)}

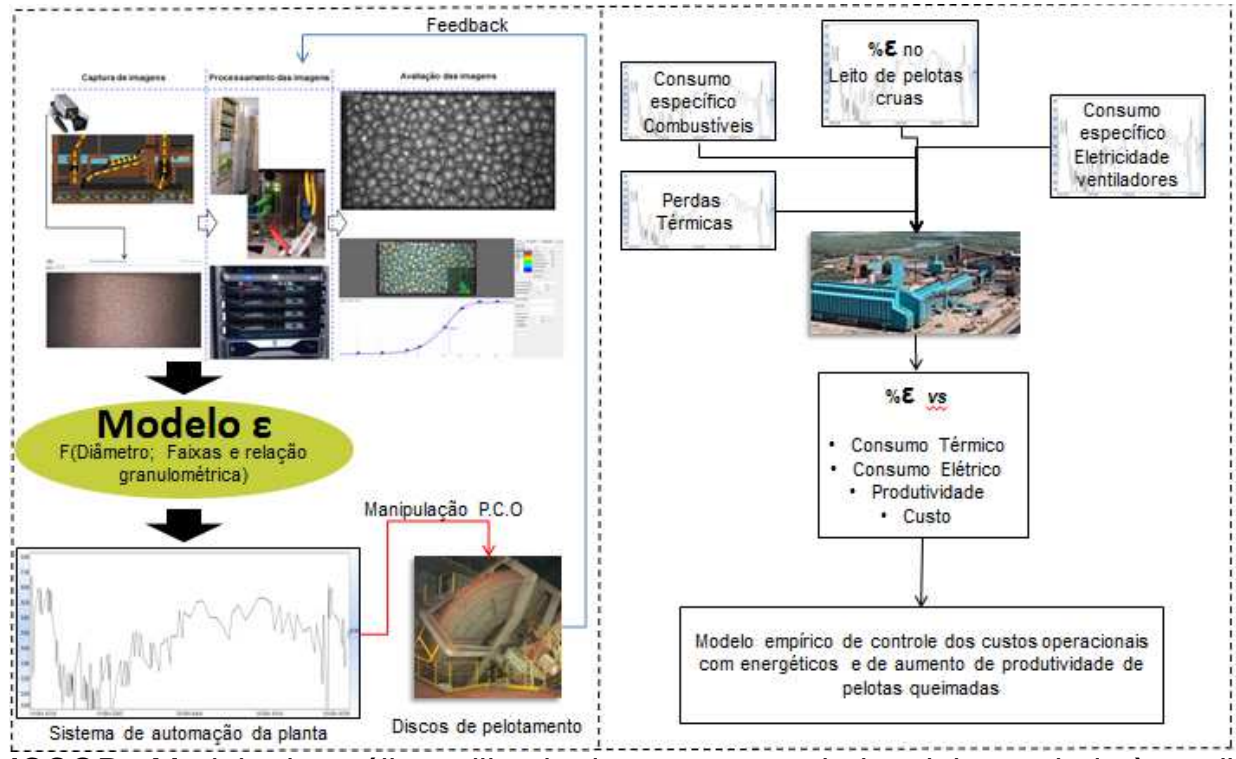

Figura 7. MCCOOP - Modelo de análise utilizado durante o teste industrial, acoplado à medição online de granulometria Optvision Pellet ${ }^{\ominus}[9]$.

\section{RESULTADOS E DISCUSSÃO}

\subsection{Redução do Consumo Específico de Carvão, Gás Natural e Energia Elétrica no Processo Produtivo com o Aumento dos \%ع:}
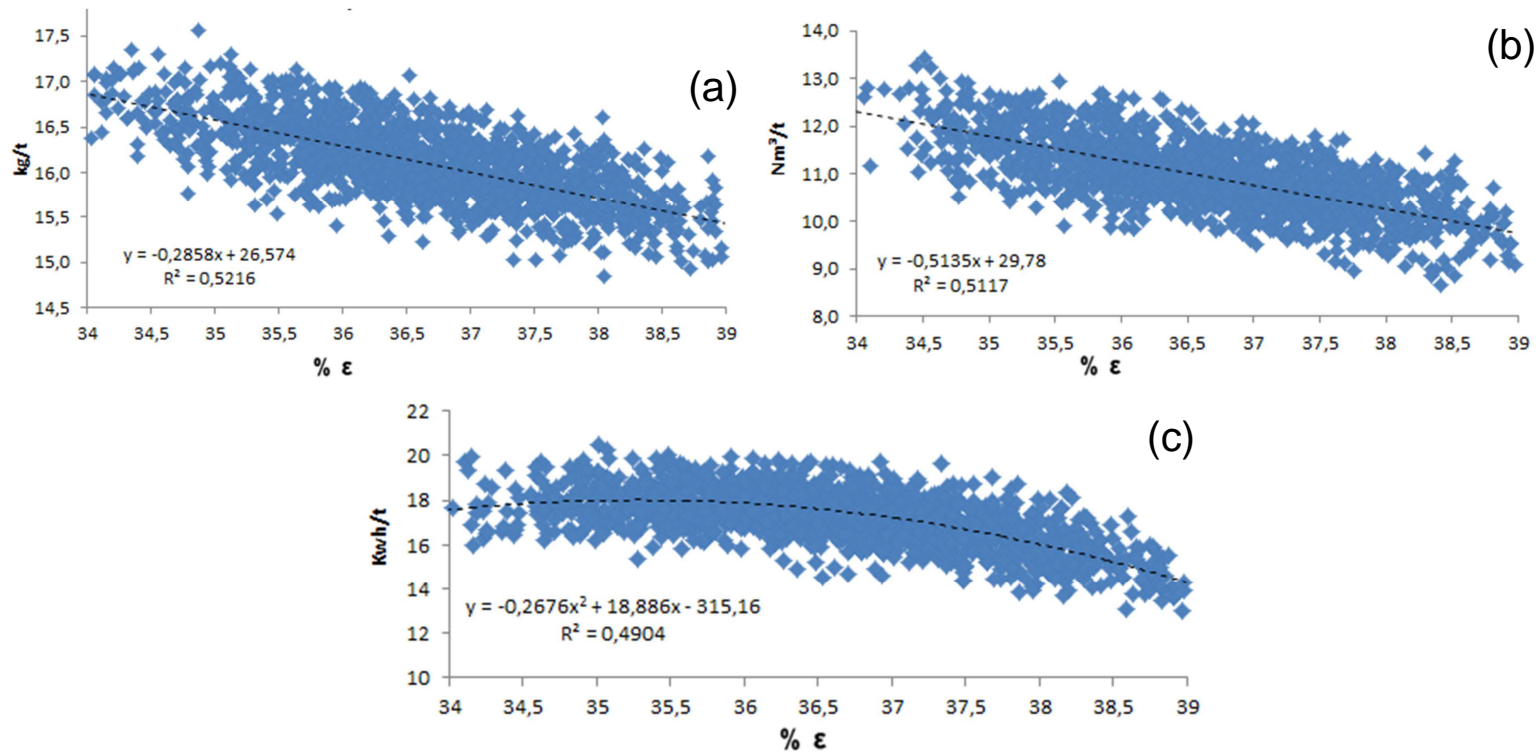

Figura 8. Efeito do \%£ no consumo específico de carvão (a), consumo específico de gás natural (b) e redução do consumo de energia elétrica dos ventiladores (c). 
3.2. Desvio do Custo Planejado com Combustíveis para o Ano em Função do $\% \varepsilon$ :

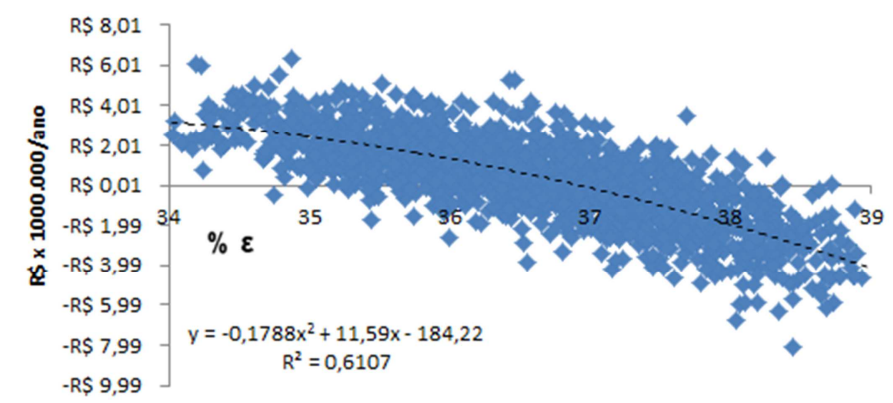

Figura 9. Efeito do \% $\varepsilon$ no Incremento no custo/ano por perdas térmicas na descarga do forno.

\subsection{Desvio do Custo Planejado com Energia Elétrica para o Ano em Função} do \%

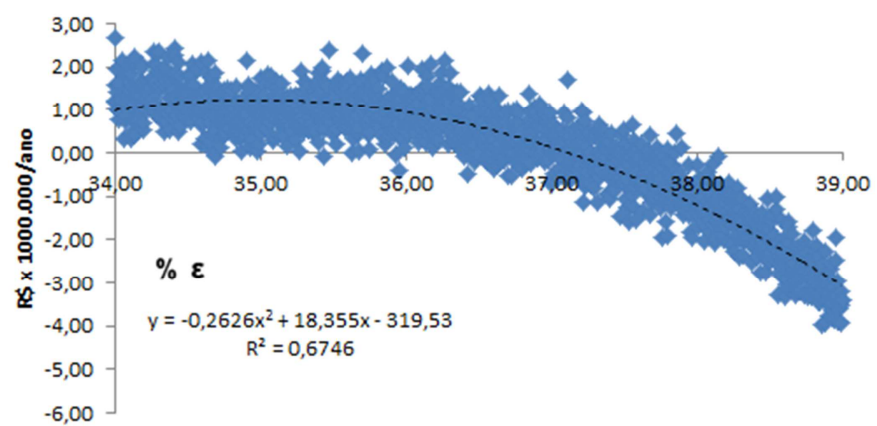

Figura 10. Efeito do \% $\varepsilon$ no custo específico de energia elétrica dos ventiladores de processo.

\subsection{Efeito do \%ع sobre a Produtividade}

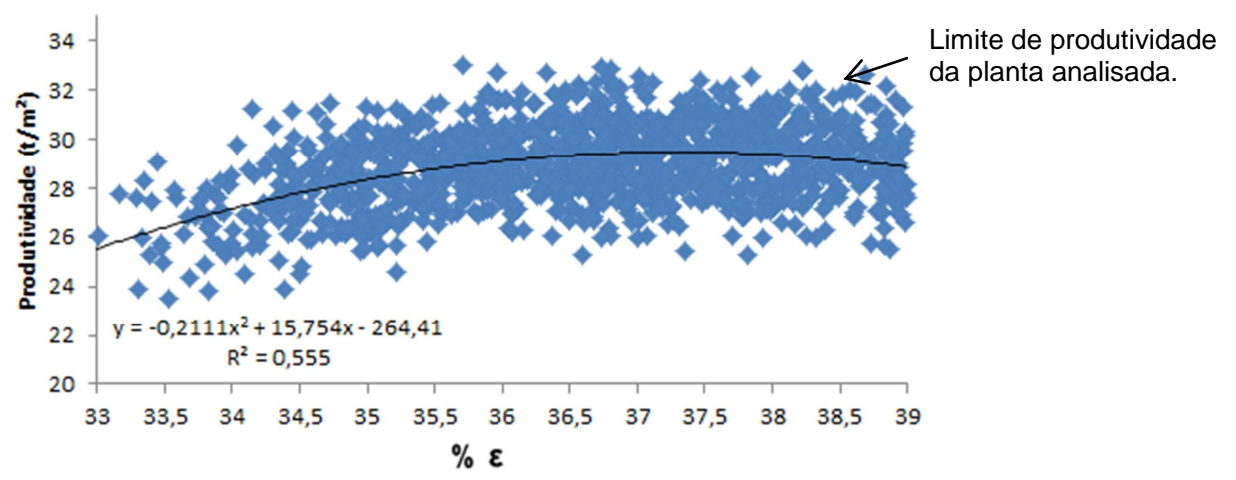

Figura 11. Efeito do \% $\varepsilon$ na produtividade.

Nota 1: A produtividade de um forno de grelha móvel [t/m²] é dita como a taxa de pelotas queimadas produzidas em um dia dividida pela área útil de grelha que o forno dispõe, neste estudo a produtividade é a tendência da taxa de produção de pelotas queimadas para 24 horas (medida a cada 20 minutos) dividida pela área útil de grelha. 
Nota 2: A produtividade é uma função direta das restrições de qualidade física a compressão [kgf/pelota] e ao tamboramento [\%], portanto garantir qualidade física é garantir produtividade.

\subsection{Tendências Observadas das Variáveis Envolvidas neste Estudo}

Tabela 1. Tendências encontradas dos P.C.O na unidade de processo pelotamento:

\begin{tabular}{|c|c|c|c|c|c|}
\hline \multirow{2}{*}{ P.C.O (Pelotamento) } & \multicolumn{5}{|c|}{ Tendências observadas nos P.C.O na linha de produção com incremento dos itens: } \\
\hline & Umidade [\%] & Blaine $\left[\mathrm{g} / \mathrm{cm}^{2}\right]$ & Rotaçāo(RPMI) & Inclinaçāo[0 & A Alimentaçāo[th] \\
\hline Faixa $+16.0 \mathrm{~mm}[\%]$ & & & & & \\
\hline Faixa $-16.0+8.0 \mathrm{~mm}[\%]$ & & & & & \\
\hline Faixa $-8.0+6.3 \mathrm{~mm}[\%]$ & & & & & \\
\hline Faixa $-6.3 \mathrm{~mm}[\%]$ & & & & & \\
\hline Diâmetro Médio [mm] & & & & & \\
\hline Relação Granulométrica [-] & & & & & \\
\hline
\end{tabular}

Tabela 2. Tendências do \% $\%$, leito, forno e qualidade quando alterado os P.C.O:

\begin{tabular}{|c|c|c|c|c|}
\hline \multirow[b]{2}{*}{ P.C.O (Pelotamento) } & \multicolumn{4}{|c|}{ Incremento P.C.O } \\
\hline & $\% \varepsilon$ & $\begin{array}{c}\text { Homogeinidade do } \\
\text { leito }\end{array}$ & $\begin{array}{l}\text { Tempo de residência } \\
\text { no forno }\end{array}$ & Qualidade Fisica \\
\hline Faixa +16.0 mm [\%] & $\begin{array}{l}\text { Até } 2,3 \% \text { pouca } \\
\text { influência }\end{array}$ & & & \\
\hline Faixa $-16.0+8.0 \mathrm{~mm}[\%]$ & & & $\begin{array}{l}\text { Depende diâmetro } \\
\text { médio }\end{array}$ & \\
\hline Faixa $-8.0+6.3 .0 \mathrm{~mm}[\%]$ & & & & 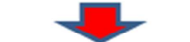 \\
\hline Faixa - $6.3 \mathrm{~mm}[\%]$ & & - & & \\
\hline Diâmetro Médio [mm] & & $\begin{array}{c}\text { Deslocamento da } \\
\text { relação } \\
\text { granulométrica }\end{array}$ & & té 12,2 \\
\hline Relação Granulométrica [-] & & $\begin{array}{l}\text { Deslocamento do } \\
\text { diâmetro médio }\end{array}$ & & té 1,0 \\
\hline
\end{tabular}

Nota 3: A relação encontrada, durante o estudo, entre o diâmetro médio da pelota queimada e o diâmetro médio da pelota crua:

Ou seja, uma pelota crua com 12,27 mm de diâmetro após passar pelo forno seu diâmetro é contraída em média para $11,87 \mathrm{~mm}$ e seu volume é reduzido em média de $9,00 \%$ considerando os minérios e perfil térmico utilizado.

\subsection{Modelo Empírico de Controle dos Custos Operacionais com Energéticos e de Aumento de Produtividade de Pelotas Queimadas em Função do \%๕}

A esfera amarela indica o ponto em que o custo anual com combustíveis e energia elétrica (energéticos) está aderente ao desembolso planejado anual, já a esfera verde indica o ponto ótimo onde mostra o momento de maior produtividade e ainda com os custos com energéticos bem abaixo do planejado anual. 


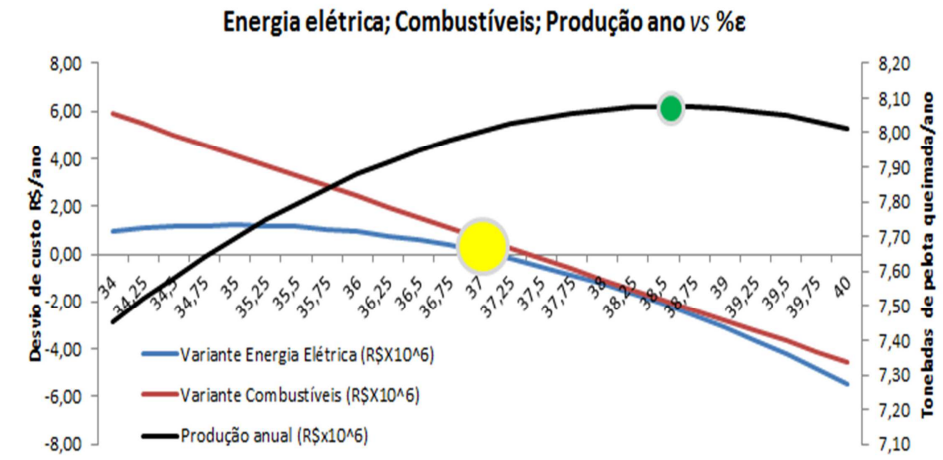

Figura 12. Efeito do \%£ no custo com combustíveis, energia elétrica e produtividade.

Produção ano de pelotas [(toneladas/ano)x $\left.10^{6}\right]=-0,03 \% \varepsilon^{2}+2,3132 \% \varepsilon-36,519$

Incremento custo variável combustíveis $\left[(R \$ / a n o) \times 10^{6}\right]=-1,7361 \% \varepsilon+64,905$

Incremento custo variável energia elétrica $\left[(R \$ /\right.$ ano $\left.) \times 10^{6}\right]=-0,2626 \% \varepsilon^{2}+18,355 \% \varepsilon-19,53$

Utilizando o Solver do Excel encontramos alguns números interessantes:

$\% \varepsilon=34,0 \% \rightarrow$ Produção: $7.44 \mathrm{Mt} / \mathrm{ano}$; Desvios com custos: + R\$ 6.7 Milhões/ano;

$\% \varepsilon=37,0 \% \rightarrow$ Produção: $8.00 \mathrm{Mt} /$ ano; Desvios com custos: $\mathrm{R} \$ 0.00$ Milhões/ano;

$\% \varepsilon=38,5 \% \rightarrow$ Produção: $8.10 \mathrm{Mt} /$ ano; Desvios com custos: - $\mathrm{R} \$ 5.1$ Milhões/ano.

O impacto da variação de $7,44 \mathrm{Mt} /$ ano para $8,10 \mathrm{Mt} /$ ano equivale a $8,00 \%$ da receita anual planejada.

Ainda utilizando o Solve do Excel, e como pode ser visto na figura 12, após \%ع = $38,55 \%$ a produção anual estimada é levemente decrementada, isso em função da tendência de queda da qualidade física á compressão, agente restritivo de produção, que pode ser explicada por dois vieses distintos;

1) (Tempo de residência) Com o aumento do \%ع a densidade aparente do leito cai significativamente, e na planta industrial, isso faz com que a velocidade da grelha seja incrementada e naturalmente ocorre à redução do tempo de residência das pelotas nas zonas de tratamento térmico, e desta forma para alimentação constante, ocorre um decremento na qualidade física, e consequentemente ocorre a redução da carga da grelha, reduzindo então a produtividade do forno.

2) (Aumento do raio médio das pelotas) Com o aumento do \%ع é possível que o processo de secagem possa ser ineficiente em função da elevação do raio médio das pelotas, mecanismo de controle da secagem da pelota, Pereira e Seshadri [10], e com isso, reduzir o desempenho da queima das pelotas cruas.

Nota 4: Apesar do \% garantir as condições ideais, fluído dinamicamente falando para a transferência de calor no leito, a produtividade é restringida pela cinética da secagem e sinterização das pelotas cruas impostas pelos limites da planta em regime de alta produtividade.

\subsection{Informações Importantes das Médias dos Insumos e das Variáveis de Processo Durante o Período do Teste Industrial}

- (Finos/Pellet-Feed) Umidade média: 10.65 [\%];

- (Finos/ Pellet-Feed) Blaine médio: $1973\left[\mathrm{~g} / \mathrm{cm}^{2}\right]$;

- (Finos/ Pellet-Feed) -325\# médio: 89.80 [\%]; 
- (Finos/ Pellet-Feed) Hematita especular média: 38.46 [\%];

- (Finos/ Pellet-Feed) PPC médio: 3.19 [\%];

- (Forno) Perfil térmico queima único durante todo o teste: $1330\left[{ }^{\circ} \mathrm{C}\right]$;

- (Forno) Camada de fundo: 0.06 [m];

- (Forno) Camada total do leito: 0.45 [m];

\section{CONCLUSÃO}

O presente estudo validado como teste industrial apresentou importantes informações no que tange aos custos e a produtividade na pelotização, conforme mostrado no item 3.6 e na figura 11. A partir da manipulação de alguns parâmetros de controle operacional, também chamados de P.C.O, tais como diâmetro médio, faixas e relação granulométrica, o \% resultante do empacotamento das pelotas cruas previamente produzidas pelo pelotamento em carros de grelha, pode ser manipulado de tal forma que permita condições ideais de fluído dinâmica e cinética para garantir o tratamento térmico adequado destes aglomerados durante sua passagem pelo forno, conforme mostrado na tabela 2. A performance energética de um forno tipo grelha móvel, além da adequada manutenção, demonstrou-se está intimamente ligada ao \% e a otimização desta métrica significa redução dos custos com insumos energéticos de até cinco milhões de reais por ano, sobre o planejado, e ainda no aumento da receita da empresa com o incremento de produção, em função da boa qualidade física performada pela planta estudada, de até oito por cento. É importante comentar que a redução de energéticos implica na redução de poluentes gasosos emitidos pelo forno e ainda no consumo consciente de energia elétrica em um período de baixos reservatórios de água no país destinado para produção de energia elétrica.

Como próximo passo é sugerido o estudo de perfis diferenciados de temperatura na queima e à análise de degradação das pelotas queimadas, tendo como premissa a qualidade física adequada, variando o diâmetro médio para se determinar os diâmetros limites que permitam o menor nível de degradação das pelotas visando o bom rendimento dos processos posteriores ao da queima e peneiramento das pelotas, tais como estocagem, transporte, e carregamento nos reatores de nossos clientes.

\section{Agradecimentos}

Agradecemos a todos os envolvidos no estudo, em especial aos colaboradores da automação e instrumentação, engenharia de processo e da produção da Samarco Mineração Unidade Ubu, ao professor e Ph.D. Renato Minelli Figueira pela orientação deste estudo que foi parte integrante da produção acadêmica de mestrado realizado via programa de pós-graduação em engenharia metalúrgica, materiais e de minas da UFMG, e ao CNPq, CAPES-PROEX e FAPEMIG.

\section{REFERÊNCIAS}

1 Disponível em: www.vale.com/PT/business/mining/iron-ore-pellets/Paginas/Iron-OreIndices.aspx, Janeiro de 2015.

2 NUNES, S.F.,Influência da carga recirculante do pelotamento na qualidade física das pelotas cruas e queimadas da Samarco Mineração S.A, Ouro Preto: REDEMAT-UFOP, 2007, 118p (Dissertação, Mestrado em Engenharia de Materiais). 
3 MEYER, K. Pelletizing of Iron Ores; Springer. Verlag Berlin. Heidelberg, and Verlag Stahleissen mbH, Düsseldorf, Germany, 1980.

4 Samarco Mineração SA. Manual Integrado da Gerência de Produção de Ubu. 2013. Revisão 01:34-38.

5 FONSECA, M. C., Influência da distribuição granulométrica do pellet feed no processo de aglomeração e na qualidade da pelota de minério de ferro para redução direta, Ouro Preto: REDEMAT-UFOP, 2004, 126p (Dissertação, Mestrado em Engenharia de Materiais).

6 MATOS, A.P., Influência da temperatura, pressão, produção e granulometria no processo de secagem das pelotas cruas, Ouro Preto: REDEMAT-UFOP, 2007, 115p (Dissertação, Mestrado em Engenharia de Materiais).

7 ATHAYDE, M., Avaliação da distribuição de gases em forno de pelotização da Samarco Mineração através de CFD e validação experimental, 43 Seminário de redução de minério de ferro e matérias-primas \& 14 Simpósio brasileiro de minério de ferro, 2013.

8 FLAMANT, G.F., FATAH N., FLITRIS Y., Wall-to-bed heat transfer in gas-solid fluidized beds: prediction of heat transfer regimes, Powder Technology, Vol 69, p.223-230, Janeiro 1992.

9 Disponível em: http://www.cemi.eng.br/br/opt03.php.

10 PEREIRA, R. O. S.; SESHADRI, V. Secagem de pelotas de minério de ferro. Metalurgia ABM, v. 41, p. 141-144, 1985. 